\title{
UM ESTUDO SOBRE A APLICAÇÃO DOS CONCEITOS E ELEMENTOS DA INDÚSTRIA 4.0 NA PRODUÇÃO DE BIOMEDICAMENTOS
}

\section{A STUDY ABOUT THE APPLICATION OF INDUSTRY 4.0 CONCEPTS AND ELEMENTS IN BIOMEDICINE PRODUCTION}

\author{
Felipe Silva* E-mail: felipe.silva@ua.pt \\ Marlene Amorim* E-mail: mamorim@ua.pt \\ David Resende** E-mail: david@ua.pt \\ *GOVCOPP/DEGEIT, Universidade de Aveiro, Portugal \\ ${ }^{* *}$ GOVCOPP/ESTGA, Universidade de Aveiro, Portugal
}

\begin{abstract}
Resumo: Esse estudo descreve uma revisão sistemática da literatura sobre a aplicação dos conceitos e elementos da Indústria 4.0(14.0) na produção de medicamentos a partir de processos biotecnológicos. O termo "indústria 4.0" trata da quarta revolução industrial atualmente em curso. Um dos seus objetivos é a integração entre o mundo real e virtual através da adoção de Sistemas Ciberfísicos, Internet das Coisas e outros elementos tecnológicos propostos pela 14.0. A revisão sistemática considerou publicações até agosto de 2019, sem restrição de data de início, por ser um assunto relativamente recente. Os resultados mostram numerosos documentos publicados sobre o tema 14.0, porém poucos relacionados à indústria biofarmacêutica. Os principais documentos obtidos através da revisão são discutidos ao longo deste artigo. A maioria das publicações aplicadas ao campo biofarmacêutico ainda se encontra em revistas e jornais especializados, provavelmente por causa da incipiência do assunto. Os anos de publicação dos documentos incluídos neste estudo através da revisão sistemática na literatura reforçam essa incipiência. Todas as publicações foram feitas nos últimos 5 anos. Esse fato sugere oportunidades interessantes para realização e publicação de novas pesquisas sobre o assunto nas bases científicas estabelecidas.
\end{abstract}

Palavras-chave: Industry 4.0. Pharma 4.0. Biopharma 4.0. Bio 4.0.

Abstract: This study proposes a systematic literature review on the application of Industry 4.0(14.0) concepts and elements in the production of biomedicines. The term "industry 4.0" refers to the fourth industrial revolution that is currently underway. Among other factors, the central objective is the integration between the real and the virtual world through Cyber Physical Systems (CPS), Internet of Things (IOT) and other technological elements. The systematic review considered publications up to July 2019, without restriction of start date, as being a relatively recent subject. The results show numerous published papers on the topic 14.0, but few focused on the biopharmaceutical industry. Key documents obtained through systematic review are also discussed throughout this article. Most publications on 14.0 applied to the biopharmaceutical field are still localized in specialized journals, probably because of the incipience of the subject. This fact suggests interesting opportunities for new research on the subject in the established scientific bases.

Keywords: Industry 4.0. Pharma 4.0. Biopharma 4.0. Bio 4.0. 


\section{INTRODUÇÃO}

\subsection{A Indústria 4.0}

Os termos "manufatura avançada" ou "indústria 4.0" (14.0) têm sido amplamente mencionados na literatura geral e estão diretamente relacionados ao futuro da manufatura e da manutenção da competitividade industrial. O mundo está atualmente frente à uma nova revolução industrial a ocorrer em um ritmo mais acelerado do que as anteriores (Figura 1). Dentre outros fatores, a fundamentação da 14.0 estaria na fusão ou integração entre o mundo virtual e o mundo real por meio da adoção de Sistemas Ciberfísicos (CPS) e da Internet das Coisas (IoT), permitindo maior grau de automação e digitalização dos processos produtivos. A loT permite que o CPS estabeleça comunicação entre equipamentos, processos e seres humanos, permitindo, por exemplo, tomadas de decisões descentralizadas em tempo real.

O termo 14.0 originou-se de um projeto associado à estratégia de alta tecnologia do governo alemão destinado à informatização e digitalização da indústria. Na edição de 2011 da Feira de Hannover, a 14.0 é proposta como o cruzamento das fronteiras entre os mundos digital, físico e biológico. Esses conceitos foram formalmente ampliados em 2013 em um documento desenvolvido pela Acatech (Academia Nacional Alemã de Ciência e Engenharia) (DAUDT; WILLCOX, 2016).

Figura 1 - Revoluções Industriais

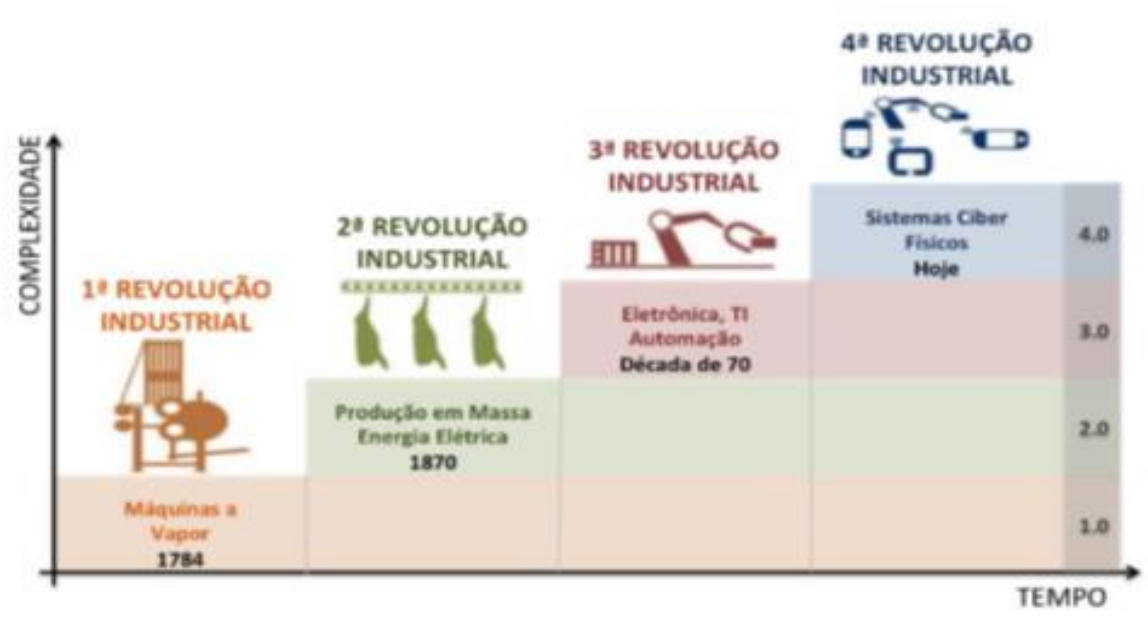

Fonte: Coelho (2016) 
A 14.0 propõe a implementação de fábricas inteligentes, estruturadas em torno de linhas de produção modulares e flexíveis. Tais fábricas empregam CPS (composto de computação integrada, redes e componentes físicos, tais como sensores) para monitorar processos, maximizar a produtividade através de modelos virtuais, melhorar os serviços desejados pelas empresas em várias áreas e operar com a opção de tomadas de decisões descentralizadas (HAMMER, 2018).

As aplicações e soluções de tecnologia da informação e digitalização em processos industriais são muitas e estão evoluindo rapidamente. A capacidade das máquinas de monitorar, analisar, prever e automatizar a fabricação em tempo real permitiu às empresas pensarem e estudarem cuidadosamente modelos usados para otimizar processos, aumentar a produtividade, evitar falhas, melhorar a flexibilidade, personalizar produtos, reduzir riscos, atenuar gastos com atividades humanas, minimizar consumo de energia, dentre outros (DAUDT; WILLCOX, 2016). Somente na Alemanha, onde a Indústria 4.0 encontra-se mais avançada, estimam-se ganhos de produtividade entre $15 \%$ a $25 \%$ (TESSARINI; SALTORATO, 2018).

De acordo com HAMMER (2018) para tirar o máximo proveito dos elementos e conceitos da 14.0, as soluções industriais devem seguir quatro princípios básicos:

1. Interoperabilidade: capacidade das máquinas e processos de interagir diretamente entre si.

2. Transparência e utilização da informação: capacidade dos sistemas de informação de criar modelos virtuais, combinando sistemas digitais de plantas e dados de sensores em tempo real, para que possam ser facilmente analisados e resultar automaticamente na tomada de decisões;

3. Assistência Técnica: Capacidade de agregar dados e visualizar automaticamente as informações para prever e resolver problemas;

4. Decisões descentralizadas: O uso do CPS permite a tomada de decisões e a execução de tarefas de forma autônoma, delegando apenas aos seres humanos em circunstâncias excepcionais.

Como a consolidação dos conceitos da 14.0 ainda está em andamento, qualquer tentativa de classificar seus elementos se torna complexa. De uma forma geral, os elementos fundamentais da 14.0 são considerados o CPS, a IoT e a Internet de Serviços (loS). Como esse estudo foca nos processos produtivos 
industriais, optou-se por detalhar como elementos fundamentais apenas o CPS e a IoT. As tecnologias que permitem a aplicabilidade dos conceitos 14.0 (alguns autores descrevem como elementos estruturantes) incluem Automação, Comunicação Máquina a Máquina (M2M), Inteligência Artificial, Big Data, Computação em Nuvem, Integração de Sistemas e Segurança Cibernética. Finalmente, os elementos complementares são aqueles que aumentam as possibilidades de aplicação do 14.0, mas não são estritamente necessários. Podem incluir a utilização de robôs inteligentes, impressão 3D, etiqueta RFID, código $Q R$, realidade virtual ou aumentada, dentre outros (SACOMANO; SÁTYRO, 2018a).

\subsection{A Indústria biofarmacêutica 4.0}

O setor de medicamentos biotecnológicos começou a divergir da indústria dos farmoquímicos ao final da Segunda Guerra Mundial, quando o conhecimento da biotecnologia começou a desempenhar papel cada vez mais significativo na produção de medicamentos e vacinas. Atualmente, as drogas de origem biológica respondem por uma fatia crescente do mercado farmacêutico, impulsionadas por investimentos cada vez mais significativos em inovação tecnológica na área de moléculas e compostos obtidos a partir de maquinário celular em processos biotecnológicos. Segundo Rader \& Langer (2018), o crescimento da receita de produtos biofarmacêuticos encontra-se na faixa de $12 \%$ a $15 \%$ ao ano (duas vezes mais rápido do que os farmoquímicos).

As plataformas tecnológicas utilizadas para os medicamentos biotecnológicos envolvem o uso de organismos vivos, atenuados ou inativados, inteiros ou em subunidades, geneticamente modificados ou não, para a produção de vacinas ou biofarmacos em quantidades industriais. A produção desses biomedicamentos requer um desafio tecnológico extraordinário, envolvendo atividades onerosas e sofisticadas que incluem processos de cultivo celular, sistemas de purificação de alto desempenho, controle de qualidade altamente sensíveis, dentre outras plataformas complexas (SILVA; CAULLIRAUX, 2016).

O setor de produção de biomedicamentos apresenta diversas particularidades que o qualifica para a aplicação dos princípios da 14.0. Uma das características 
importantes resulta do risco potencial da intervenção de operadores da área por serem importantes fontes de contaminação externa em processos que exigem assepsia ou esterilidade. A entrada de um único contaminante na produção de um lote de vacina pode causar um prejuízo milionário. A tendência é que linhas produtivas mais automatizadas fiquem mais protegidas do fator humano $e$ consequentemente reduzam episódios de contaminação. Outra forte peculiaridade dessa área é a possibilidade de obter produtos instáveis devido à imprevisibilidade da produção em sistemas vivos. Diferentemente dos processos farmoquímicos, onde os processos são geralmente mais previsíveis, uma instabilidade genética simples e inesperada de um organismo hospedeiro específico, por exemplo, pode alterar toda a composição molecular e consequentemente atividade farmacológica de um biomedicamento (SILVA; CAULLIRAUX, 2016). Logo, a possibilidade de monitoramento rigoroso e controle em tempo real desses sistemas, é de grande valia para esse setor.

Embora o tema 14.0 já seja amplamente explorado em algumas áreas, em outros setores específicos seguem um ritmo mais lento. Com base nessa premissa, este artigo tem por objetivo identificar, através de uma revisão sistemática, o conteúdo disponível na literatura que relaciona os conceitos e elementos da 14.0 à produção de biomedicamentos.

\section{DESENVOLVIMENTO}

\subsection{Metodologia}

A metodologia proposta por esse estudo envolveu uma detalhada revisão sistemática na literatura (RSL) realizada entre maio e agosto de 2019. A pesquisa explorou as principais bases de dados científicos e periódicos especializados nas áreas de saúde, produção de medicamentos e gestão de empresas biofarmacêuticas.

A pergunta central formulada para identificar, selecionar e avaliar criticamente estudos e documentos relevantes sobre o tema pesquisado foi a seguinte:

Qual a disponibilidade de conteúdo documental sobre o tema 14.0 aplicado à indústria biofarmacêutica na literatura científica ou especializada? 
Segundo Barbosa (2009), a sistematização científica é a única maneira de não se perder na complexidade do fenômeno a ser estudado.

Figura 2 - Etapas de uma revisão sistemática de literatura

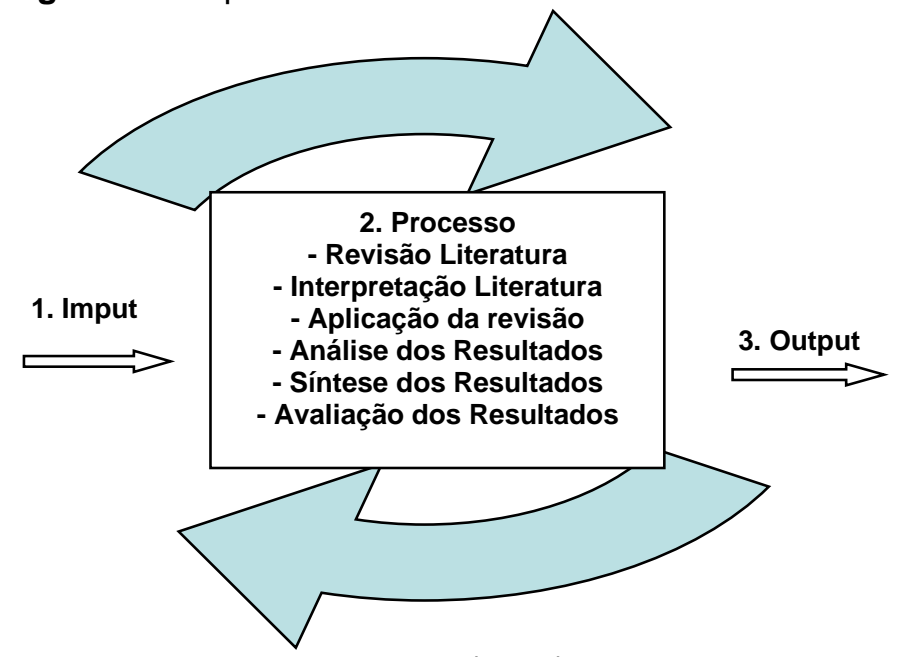

Fonte: Adaptado de Barbosa (2009).

Inicialmente, realizou-se uma pesquisa bibliográfica de caráter exploratório sem o rigor de uma RSL e com o objetivo de identificação de fontes primárias. Essas consistem em artigos, periódicos ou bancos de dados úteis para definir palavraschave, identificar autores-chave e artigos relevantes, contextualizar o tema e fornecer uma ideia inicial sobre o tópico (Quadro 1). Além dos documentos identificados por essa revisão inicial, outros foram coletados por recomendação de pesquisadores, professores, especialistas da área, entre outros.

Quadro 1 - Principais fontes primárias coletadas e utilizadas

\begin{tabular}{|c|c|c|}
\hline Autores & Documentos & Utilidade \\
\hline Barbosa (2009) & $\begin{array}{c}\text { A Formação de Competências para Inovar através de } \\
\text { Processos de Transferência de Tecnologia: um estudo de caso }\end{array}$ & $\begin{array}{c}\text { Introdução } \\
\text { Metodologia }\end{array}$ \\
\hline $\begin{array}{c}\text { Conforto; } \\
\text { Amaral; } \\
\text { Silva (2011) }\end{array}$ & $\begin{array}{r}\text { Roteiro para revisão bibliográfica sistemática: no } \\
\text { desenvolvimento de produtos e GP }\end{array}$ & Metodologia \\
\hline $\begin{array}{c}\text { Daudt; Willcox } \\
\text { (2016) }\end{array}$ & $\begin{array}{r}\text { Reflexões críticas a partir das experiências dos Estados Unidos } \\
\text { e da Alemanha em manufatura avançada }\end{array}$ & $\begin{array}{c}\text { Introdução } \\
\text { Palavras chaves } \\
\text { Resultados } \\
\text { Discussão }\end{array}$ \\
\hline $\begin{array}{c}\text { Oztemel; } \\
\text { Gursev (2018) }\end{array}$ & Literature review of Industry 4.0 and related technologies & $\begin{array}{c}\text { Palavras chaves } \\
\text { Principais autores } \\
\text { Resultados } \\
\text { Discussão }\end{array}$ \\
\hline $\begin{array}{c}\text { Rader; Langer } \\
\text { (2018) }\end{array}$ & Biopharma Manufacturing Markets & \begin{tabular}{c} 
Introdução \\
\hline Sacomano;
\end{tabular} \\
Sátyro (2018a) & Indústria 4.0: conceitos e elementos formadores & $\begin{array}{c}\text { Introdução } \\
\text { Resultados } \\
\text { Discussão }\end{array}$ \\
\hline
\end{tabular}


Quadro 1 - Principais fontes primárias coletadas e utilizadas

\begin{tabular}{|c|c|l|}
\hline Autores & Documentos & Utilidade \\
\hline $\begin{array}{c}\text { Silva; Caulliraux } \\
(2016)\end{array}$ & $\begin{array}{c}\text { Desverticalização das cadeias produtivas no setor de produção } \\
\text { de biomedicamentos e a utilização das empresas CMOs }\end{array}$ & Introdução \\
\hline $\begin{array}{c}\text { Tessarini; } \\
\text { Saltorato (2018) }\end{array}$ & $\begin{array}{c}\text { Impactos da indústria 4.0 na organização do trabalho: uma } \\
\text { revisão sistemática da literatura }\end{array}$ & $\begin{array}{c}\text { Introdução } \\
\text { Resultados } \\
\text { Discussão }\end{array}$ \\
\hline
\end{tabular}

Fonte: Elaboração Própria

Após a identificação e coleta das chamadas fontes primárias, a RSL foi iniciada nas bases científicas Science Direct, Emerald, Scopus e Web of Science. À medida em que a pesquisa avançava, verificava-se que havia uma quantidade significativa de material também em revistas e periódicos eletrônicos especializados nas áreas-alvo. Assim, a pesquisa também foi realizada nos periódicos eletrônicos da Sociedade Internacional de Engenharia Farmacêutica (ISPE), Pharmtech (Pharm), Biopharm International (BP) e American Pharmaceutical Review (APR). Conforme ilustrado na Figura 3 , todas essas fontes foram utilizadas para identificação, seleção e inclusão de documentos a serem aproveitados sobre o tema de pesquisa. Os termos chaves utilizados para a busca (digitalizados com aspas ou usando o conector AND) foram "Industry 4.0", "Pharma 4.0", "Biopharma 4.0" e "Bio 4.0".

Figura 3 - Processo para obtenção dos documentos selecionados/incluídos na RSL

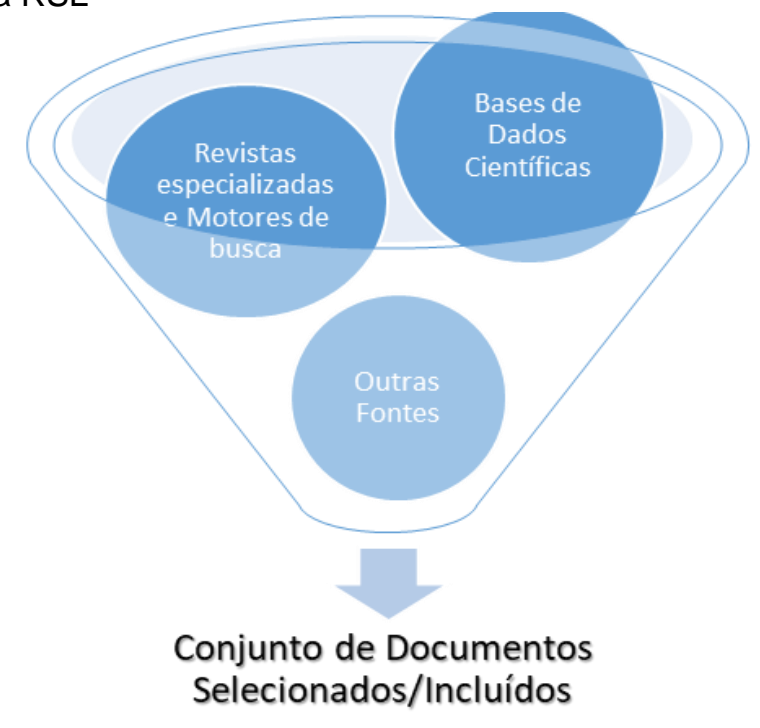

Fonte: Elaboração Própria

Como ilustrado na Figura 4, os chamados documentos "identificados" foram todos aqueles encontrados pelos mecanismos de pesquisa sem qualquer avaliação 
prévia. Os estudos "não selecionados" foram aqueles que não atendiam à questão de pesquisa definida anteriormente. $O$ oposto disso ocorreu com os estudos "selecionados". Selecionou-se os estudos que numa análise preliminar (avaliados por título e resumo) atendiam aos anseios da questão de pesquisa estabelecida. Os estudos "excluídos" foram aqueles que não estavam disponíveis em todo o seu conteúdo, os que apareceram repetidos em mais de um banco de dados ou que, após avaliação em texto completo, não atenderam aos anseios da pergunta de pesquisa. Por fim, os estudos "incluídos" foram aqueles que, após avaliação de texto completo, atenderam aos critérios de inclusão.

Figura 4 - Processo de coleta de documentos - RSL

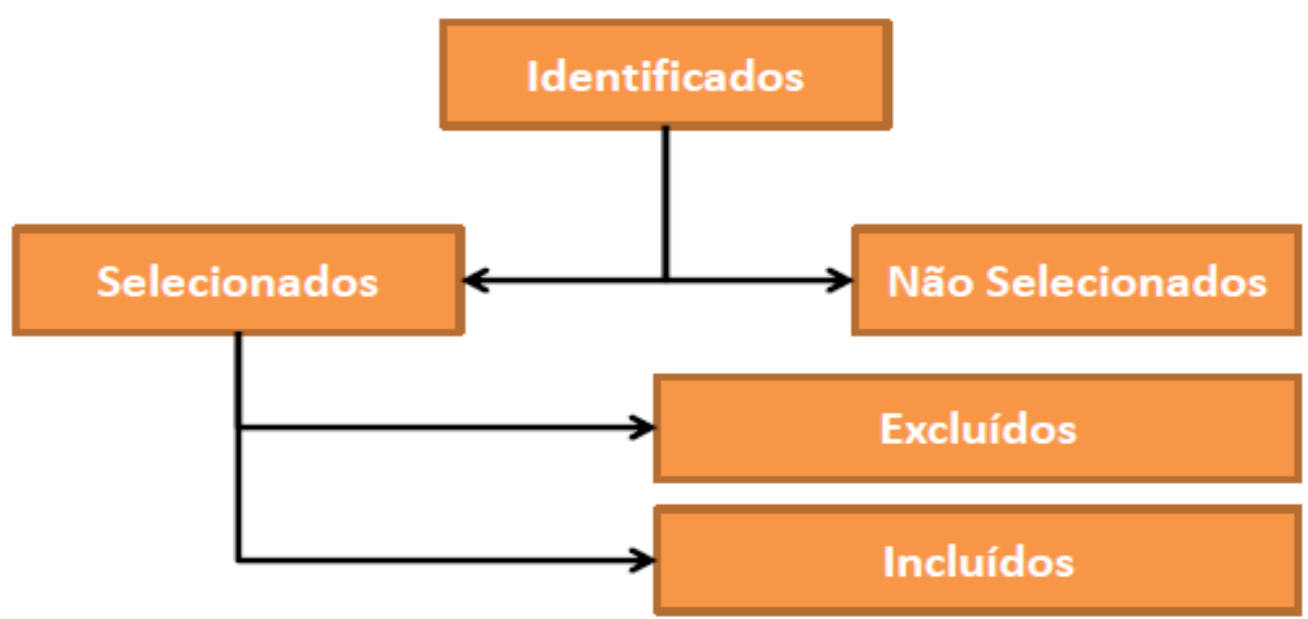

Fonte: Elaboração Própria

Os resultados obtidos através da RSL seguem dispostos no item a seguir.

\subsection{Resultados}

Inicialmente, o termo "Industry 4.0" foi utilizado para que todos os artigos relacionados ao tema pudessem ser listados pelas bases científicas tradicionais. Como esperado, os resultados mostraram um número alto de documentos (Tabela 1). Esse fato confirma que, embora seja um tema relativamente recente, o assunto já é tratado muito intensamente em diversas áreas de atuação ao redor do mundo.

Em seguida, devido ao grande número de artigos encontrados com o termo "Industry 4.0", optou-se por refinar mais a busca em direção às áreas de interesse 
do estudo. Nesse sentido, foram utilizados os termos que delimitam a pesquisa para o campo de aplicação desejado (indústria biofarmacêutica). Dessa forma, foram utilizados os termos mais específicos (Pharma 4.0, Biopharma 4.0 e Bio 4.0).

Após refinamento da busca com a utilização dos termos mais específicos, um número significativamente menor de documentos foi obtido. Em seguida, apenas título, resumo e as palavras-chave de cada um deles foram lidos para uma filtragem preliminar. Os documentos que estavam alinhados com a questão de pesquisa foram encaminhados ao filtro seguinte. $\mathrm{Na}$ etapa seguinte, os documentos selecionados foram lidos e interpretados cuidadosamente em uma espécie de último filtro. Os trabalhos que passaram também por esse filtro foram considerados relevantes para a pesquisa realizada.

Tabela 1 - Número de artigos selecionados e incluídos - Bases Científicas Tradicionais

\begin{tabular}{|c|c|c|c|c|c|c|c|c|}
\hline \multirow{3}{*}{$\begin{array}{c}\text { Palavras- } \\
\text { Chaves } \\
\text { "Industry } \\
4.0 "\end{array}$} & \multicolumn{2}{|c|}{ Science Direct } & \multicolumn{2}{|c|}{ Emerald } & \multicolumn{2}{|c|}{ Scopus } & \multicolumn{2}{|c|}{ Web of Science } \\
\hline & Identif & Selec & Identif & Selec & Identif & Selec & Identif & Selec. \\
\hline & 4.030 & $\begin{array}{l}\text { Refinar } \\
\text { pesquisa }\end{array}$ & 251 & $\begin{array}{l}\text { Refinar } \\
\text { pesquisa }\end{array}$ & 5.068 & $\begin{array}{c}\text { Refinar } \\
\text { pesquisa }\end{array}$ & 2.961 & $\begin{array}{c}\text { Refinar } \\
\text { pesquisa }\end{array}$ \\
\hline $\begin{array}{c}\text { "Pharma } \\
4.0 "\end{array}$ & 4 & 2 & 9 & 3 & 5 & 3 & Zero & Zero \\
\hline $\begin{array}{c}\text { “Biopharma } \\
4.0 "\end{array}$ & Zero & Zero & Zero & Zero & 1 & 1 & Zero & Zero \\
\hline "Bio 4.0" & 10 & Zero & 104 & 3 & Zero & 1 & Zero & Zero \\
\hline Incluídos & --- & 2 & --- & 2 & --- & 4 & --- & Zero \\
\hline
\end{tabular}

Fonte: Elaboração Própria

Esse momento foi também especialmente importante pois marcou o início de um processo interativo de busca cruzada, onde foram rastreados e identificados documentos relevantes a partir das referências dos trabalhos ou pelas citações dos seus autores ou conteúdo na literatura. O Quadro 2 mostra os documentos relevantes incluídos através da técnica de referências e citações: 
Quadro 2 - Artigos selecionados e incluídos pela técnica de referências e citações

\begin{tabular}{|c|c|c|}
\hline & Autor(es) & Artigos \\
\hline \multirow{4}{*}{$\begin{array}{c}\text { Por } \\
\text { Referências } \\
\text { Bibliográficas }\end{array}$} & Yu; Kopcha (2017) & The future of pharmaceutical quality and the path to \\
\cline { 2 - 3 } & getthere.
\end{tabular}

Fonte: Elaboração Própria

Através também desse processo interativo de busca cruzada, percebeu-se que parte significativa do conteúdo sobre o tema estava localizada em revistas especializadas. Sendo assim, optou-se por selecionar quatro revistas especializadas no setor estudado, e realizar nelas uma nova busca por documentos em geral que atendessem aos anseios desse estudo. Os processos de identificação, seleção e inclusão seguiram exatamente a mesma lógica utilizada para a pesquisa nas bases de dados científicas tradicionais. Entretanto, como as revistas são especializadas na área de estudo, optou-se pela utilização direta dos termos "Pharma AND 4.0" e "Bio AND 4.0". Os resultados das buscas encontram-se na tabela abaixo (Tabela 2).

Tabela 2 - Número de artigos selecionados e incluídos - Revistas Especializadas

\begin{tabular}{ccccccccc}
\hline & \multicolumn{1}{c}{$\boldsymbol{P H A R M T E C H}$} & \multicolumn{2}{c}{ ISPE } & \multicolumn{2}{c}{ BIOPHARM } & \multicolumn{2}{c}{ APR } \\
\hline Palavras-Chave & Identif & Selec. & Identif. & Selec. & Identif. & Selec. & Identif. & Selec. \\
"Pharma 4.0" & 49 & 8 & 70 & 10 & 12 & 6 & 13 & 8 \\
"Bio 4.0" & 29 & 6 & Zero & Zero & 24 & 8 & 7 & 4 \\
Incluídos & --- & 13 & -- & 9 & --- & 7 & --- & 6 \\
\hline
\end{tabular}

Fonte: Elaboração Própria

A análise e discussão dos resultados sobre o assunto pesquisado estão descritas no item a seguir.

\subsection{Análise e discussão dos resultados}

Neste item, oferece-se um resumo sobre as características e os conteúdos dos principais documentos selecionados através da RSL. Também é discutido aqui o atual estado da arte sobre o tema pesquisado, considerando o número de 
documentos selecionados e incluídos, as bases de conhecimento utilizadas para busca, as caraterísticas gerais dos artigos estudados, dentre outros pontos de interesse. As Tabelas 1 e 2, expostas no subitem anterior, ilustraram o quantitativo de documentos encontrados nas bases científicas e revistas especializadas. Nesse item destacam-se as informações e dados relevantes ao tema de pesquisa, considerando os principais documentos aproveitados na RSL.

O Quadro 3 compila os principais artigos coletados nas bases científicas tradicionais. Na base de dados do Web of Science nenhum artigo foi aproveitado. Os poucos estudos identificados nessa base estão focados em pesquisas experimentais ou área hospitalar.

Quadro 3 - Principais documentos selecionados e incluídos das bases científicas tradicionais

\begin{tabular}{|c|c|c|c|c|}
\hline $\begin{array}{c}\text { Base de } \\
\text { Dados }\end{array}$ & Autor(es) & Documentos & Assunto & $\begin{array}{c}\text { Características } \\
\text { Gerais }\end{array}$ \\
\hline \multirow[t]{2}{*}{ Emerald } & $\begin{array}{l}\text { Festa et al. } \\
\text { (2018) }\end{array}$ & $\begin{array}{l}\text { Big data for big } \\
\text { pharma: Harmonizing } \\
\text { business process } \\
\text { management to } \\
\text { enhance } \\
\text { ambidexterity }\end{array}$ & $\begin{array}{c}\text { "BigData" no } \\
\text { gerenciamento de } \\
\text { processos produtivos } \\
\text { e pipelines de } \\
\text { desenvolvimento }\end{array}$ & $\begin{array}{l}\text { Itália } \\
1 \text { Citação } \\
2018\end{array}$ \\
\hline & $\begin{array}{l}\text { Bertola; } \\
\text { Teunissen } \\
\text { (2018) }\end{array}$ & $\begin{array}{c}\text { Fashion } 4.0 . \\
\text { Innovating fashion } \\
\text { industry through } \\
\text { digital transformation }\end{array}$ & $\begin{array}{c}\text { Case de aplicação da } \\
14.0 \text { no setor de moda } \\
\text { - utilizado para } \\
\text { comparação com a } \\
\text { biofarmacêutica }\end{array}$ & $\begin{array}{l}\text { Itália (primeiro } \\
\text { autor) } \\
3 \text { Citações } \\
2018 \\
\end{array}$ \\
\hline \multirow[b]{2}{*}{$\begin{array}{l}\text { Science } \\
\text { Direct }\end{array}$} & $\begin{array}{l}\text { Keller et al. } \\
\quad(2018)\end{array}$ & $\begin{array}{c}\text { Optimized Robot } \\
\text { Systems for Future } \\
\text { Aseptic Personalized } \\
\text { Mass Production }\end{array}$ & $\begin{array}{l}\text { Validação e uso de } \\
\text { robôs em processos } \\
\text { produtivos assépticos }\end{array}$ & $\begin{array}{l}\text { Alemanha } \\
0 \text { Citação } \\
2018\end{array}$ \\
\hline & Ding (2018) & $\begin{array}{l}\text { Pharma Industry 4.0: } \\
\text { Literature review and } \\
\text { research opportunities } \\
\text { in sustainable } \\
\text { pharmaceutical } \\
\text { supply chains } \\
\end{array}$ & $\begin{array}{l}\text { I4.0 no gerenciamento } \\
\text { da cadeia de } \\
\text { suprimentos } \\
\text { farmacêutica }\end{array}$ & $\begin{array}{l}\text { Reino Unido } \\
12 \text { Citações } \\
2018\end{array}$ \\
\hline \multirow[b]{2}{*}{ Scopus } & $\begin{array}{c}\text { Nargund; } \\
\text { Guenther; } \\
\text { Mauch (2019) }\end{array}$ & $\begin{array}{c}\text { The Move toward } \\
\text { Biopharma } 4.0\end{array}$ & $\begin{array}{c}\text { Gêmeos digitais para } \\
\text { controle e análise de } \\
\text { processos } \\
\text { biotecnológicos em } \\
\text { tempo real } \\
\end{array}$ & $\begin{array}{l}\text { Stuttgart, } \\
\text { Alemanha } \\
\text { 0 Citação } \\
2019\end{array}$ \\
\hline & $\begin{array}{l}\text { Markarian, } \\
(2018 b)\end{array}$ & Pharma 4.0 & $\begin{array}{c}\text { Entrevistas com } \\
\text { executivos da área } \\
\text { sobre processos } \\
\text { biofarmacêuticos na } \\
\text { era da } 14.0 \\
\end{array}$ & $\begin{array}{l}\text { EUA } \\
0 \text { Citação } \\
2018\end{array}$ \\
\hline
\end{tabular}


Quadro 3 - Principais documentos selecionados e incluídos das bases científicas tradicionais

\begin{tabular}{|c|c|c|c|c|}
\hline $\begin{array}{c}\text { Base de } \\
\text { Dados }\end{array}$ & Autor(es) & Documentos & Assunto & $\begin{array}{c}\text { Características } \\
\text { Gerais }\end{array}$ \\
\hline \multirow{6}{*}{ Scopus } & $\begin{array}{c}\text { Romero- } \\
\text { Torres; } \\
\text { Moyne; } \\
\text { Kidambi, } \\
(2017)\end{array}$ & $\begin{array}{c}\text { Towards Pharma 4.0; } \\
\text { Leveraging Lessons } \\
\text { and Innovation from } \\
\text { Silicon Valley }\end{array}$ & $\begin{array}{c}\text { Case da I4.0 aplicada } \\
\text { em uma empresa de } \\
\text { semicondutores }\end{array}$ & $\begin{array}{c}\text { EUA } \\
\text { 3 Citações } \\
2017\end{array}$ \\
\cline { 2 - 5 } & $\begin{array}{c}\text { Hammer } \\
(2018)\end{array}$ & $\begin{array}{c}\text { Digitization \& 14.0- } \\
\text { Pharma Production }\end{array}$ & $\begin{array}{c}\text { Benefícios da } 14.0 \text { na } \\
\text { produção de } \\
\text { biofarmacêuticos }\end{array}$ & $\begin{array}{c}\text { Dusseldorf } \\
\text { Alemanha } \\
0 \text { Citações } \\
2018\end{array}$ \\
\hline
\end{tabular}

Fonte: Elaboração Própria

Seguiu-se a mesma lógica de busca nas revistas eletrônicas especializadas na indústria biofarmacêutica para identificação, seleção e inclusão de documentos a serem aproveitados. O Quadro 4 compila os principais documentos coletados e utilizados nas revistas especializadas consultadas.

Quadro 4 - Principais documentos selecionados e incluídos das bases científicas tradicionais

(continua)

\begin{tabular}{|c|c|c|c|c|}
\hline Fonte & Autor(Es) & Documentos & Principais Assuntos & Local/Ano \\
\hline \multirow{3}{*}{ APR } & $\begin{array}{l}\text { Hausner; } \\
\text { Romañach, } \\
\text { (2017) }\end{array}$ & $\begin{array}{l}\text { Progress Towards } \\
\text { Advanced } \\
\text { Pharmaceutical } \\
\text { Manufacturing }\end{array}$ & $\begin{array}{c}\text { Adaptação das } \\
\text { companhias } \\
\text { biofarmacêuticas aos } \\
\text { processos controlados } \\
\text { em tempo real - APC } \\
\text { (Advanced Process } \\
\text { Control) } \\
\end{array}$ & $\begin{array}{l}\text { EUA } \\
2017\end{array}$ \\
\hline & $\begin{array}{c}\text { Branch; } \\
\text { Ladage; } \\
\text { Tsiolis (2015) }\end{array}$ & $\begin{array}{c}\text { From Cell Culture to Cell } \\
\text { Therapy - Drug } \\
\text { Applications Continue } \\
\text { To Surge As Science } \\
\text { Grows (2015) }\end{array}$ & $\begin{array}{c}\text { Produção customizada } \\
\text { de biomedicamentos e } \\
\text { utilização da manufatura } \\
\text { aditiva }\end{array}$ & $\begin{array}{l}\text { EUA } \\
2015\end{array}$ \\
\hline & $\begin{array}{c}\text { American } \\
\text { Pharmaceutica } \\
\text { I Rewiew, } \\
\text { (2018) }\end{array}$ & $\begin{array}{c}\text { A } 20 \text { Year } \\
\text { Retrospective: The } \\
\text { Pharmaceutical Industry } \\
\text { Then and Now }\end{array}$ & $\begin{array}{l}\text { Evolução da indústria } \\
\text { farmacêutica nos } \\
\text { últimos } 20 \text { anos }\end{array}$ & $\begin{array}{l}\text { EUA } \\
2018\end{array}$ \\
\hline BP & $\begin{array}{c}\text { Markarian, } \\
(2018 a)\end{array}$ & $\begin{array}{c}\text { Industry } 4.0 \text { in } \\
\text { Biopharmaceutical } \\
\text { Manufacturing Modern } \\
\text { technologies offer } \\
\text { opportunities to increase } \\
\text { manufacturing efficiency }\end{array}$ & $\begin{array}{c}\text { Tecnologias e } \\
\text { oportunidades } \\
\text { oferecidas pela I4.0 no } \\
\text { campo biofarmacêutico }\end{array}$ & $\begin{array}{l}\text { EUA } \\
2018\end{array}$ \\
\hline
\end{tabular}


Quadro 4 - Principais documentos selecionados e incluídos das bases científicas tradicionais

(conclusão)

\begin{tabular}{|c|c|c|c|c|}
\hline Fonte & Autor(Es) & Documentos & Principais Assuntos & Local/Ano \\
\hline ISPE & $\begin{array}{c}\text { Manzano; } \\
\text { Langer (2018) }\end{array}$ & $\begin{array}{c}\text { Getting ready for } \\
\text { pharma 4.0 - Data } \\
\text { integrity in cloud and } \\
\text { big data applications }\end{array}$ & $\begin{array}{c}\text { Big Data, Artificial } \\
\text { Intelligence and } \\
\text { Machine Learning para } \\
\text { análise de dados em } \\
\text { tempo real }\end{array}$ & $\begin{array}{c}\text { Espanha } \\
\text { (primeiro } \\
\text { autor) } \\
2018\end{array}$ \\
\hline Pharm & $\begin{array}{c}\text { Markarian } \\
(2019)\end{array}$ & $\begin{array}{c}\text { Embracing the Digital } \\
\text { Factory for Bio/Pharma } \\
\text { Manufacturing }\end{array}$ & $\begin{array}{c}\text { Aumento de } \\
\text { produtividade, } \\
\text { qualidade, eficiência e } \\
\text { flexibilidade - } \\
\text { Benefícios da I4.0 }\end{array}$ & $\begin{array}{c}\text { EUA } \\
2019\end{array}$ \\
\hline
\end{tabular}

Fonte: Elaboração Própria

\subsubsection{Os elementos tecnológicos da 14.0 e a indústria biofarmacêutica}

Nesse item faz-se uma síntese dos principais elementos tecnológicos que compõem o arcabouço teórico da 14.0, considerando os documentos coletados através da RSL. Os elementos seguem a subdivisão entre fundamentais, estruturantes e complementares (Figura 5), conforme proposto na introdução desse estudo.

Figura 5 - Elementos formadores da 14.0

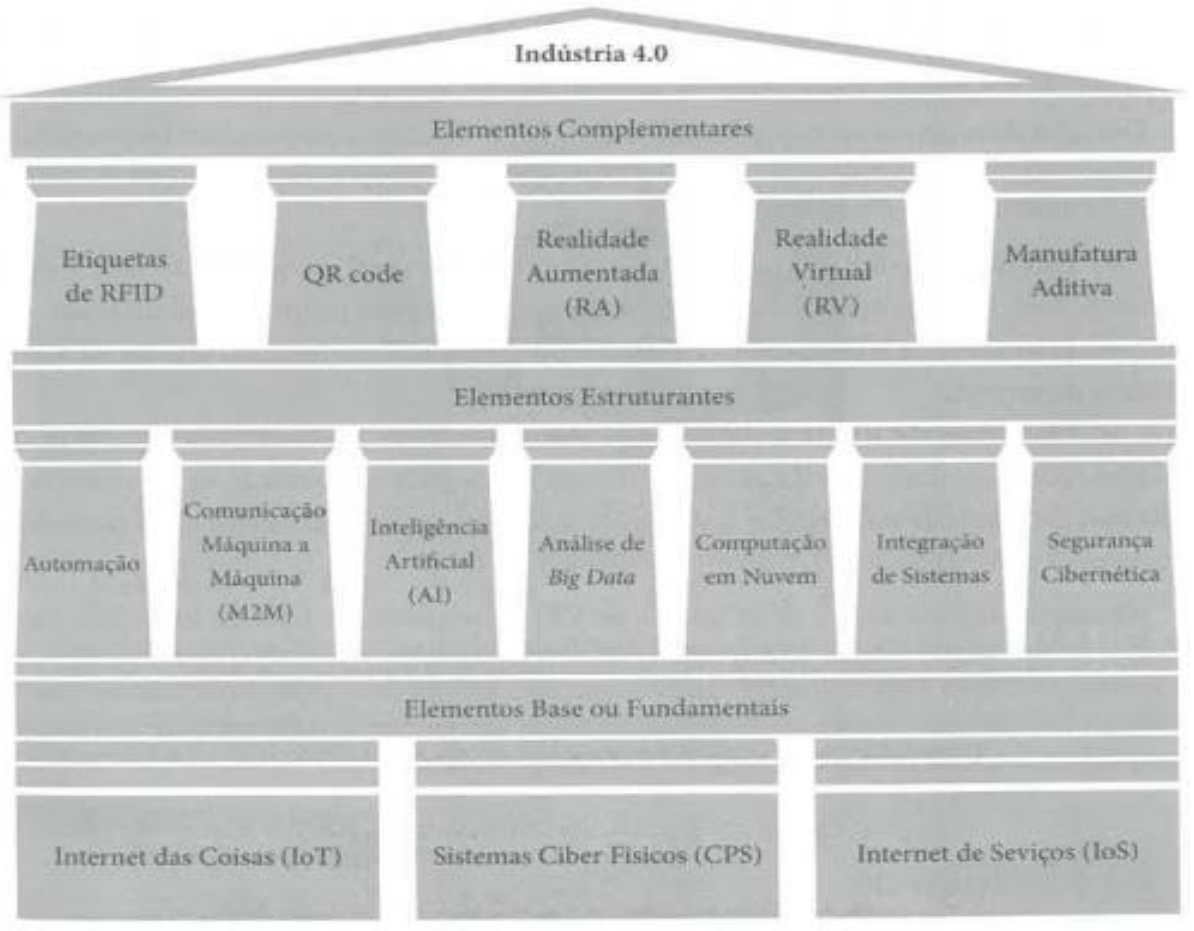

Fonte: Sacomano; Sátyro (2018b)

Revista Produção Online. Florianópolis, SC, v. 20, n. 2, p. 493-520, 2020 
Em relação aos elementos considerados fundamentais, os CPS's são sistemas mecatrônicos compostos por sensores e atuadores, controlados por softwares e que realizam o monitoramento e a supervisão de dados de processos industriais. São projetados para possibilitar o intercâmbio de informações, executar comandos e monitorar os processos de produção remotamente e em tempo real. Através deles é possível realizar simulações no processo de produção no campo virtual, sem que o físico seja comprometido e a produção prejudicada (SACOMANO; SÁTYRO, 2018a). Esses sistemas são de grande valor para a indústria biofarmacêutica, uma vez que permitem dentre outras possibilidades, o monitoramento e decisões sobre processos em tempo real com reduzida intervenção humana durante as operações.

Outro elemento tido como fundamental, a loT permite que objetos sejam detectados ou controlados remotamente através da infraestrutura de rede existente, criando oportunidades para uma integração mais direta do mundo físico aos sistemas virtuais. A loT possibilita a interconexão entre redes físicas, equipamentos de processo, dentre outros objetos com softwares, sensores, atuadores e conectividade de rede. Através da loT, os objetos "usam" a internet como canal de comunicação para coletar e trocar dados e informações em tempo real. É importante ressaltar que o perfeito funcionamento desses elementos dependerá da arquitetura e inteligência incorporadas aos sistemas pelas mãos humanas (OZTEMEL; GURSEV, 2018).

Barenji et al. (2019) avaliaram o desempenho de um sistema CPS (chamado CPbPAT) implantado em um protótipo de fábrica farmacêutica inteligente desenvolvido pela Food and Drug Administration (FDA). Foi verificado através do modelo de avaliação proposto (chamado Sistema UML) que o sistema mecatrônico foi suficientemente robusto para responder às condições normais e anormais de fabricação, adaptando-se às diversas condições de processo e inclusive tomando decisões. $O$ artigo adverte que a implementação de fábricas farmacêuticas inteligentes com tecnologias da 14.0 deve considerar previamente a necessidade de integração de sistemas e os requisitos regulatórios do setor.

Sobre os elementos tidos como estruturantes, o Big Data possui a capacidade de coletar e armazenar grande quantidade de dados em alta velocidade. Na 14.0, os 
ambientes de fabricação estão permanentemente coletando dados de multiprocessos e variados equipamentos simultaneamente em tempo real. Como resultado, a quantidade de dados coletados diariamente é enorme e variada, dos mais simples até os mais complexos, como por exemplo, provenientes de registros de lotes produtivos. Há pesquisas demonstrando que aproximadamente $70 \%$ dos dados coletados na indústria biofarmacêutica não são usados. A capacidade de usar esses dados, no entanto, dada a multiplicidade de sistemas e formatos, não é trivial e vai requerer um esforço bem coordenado com aplicação das melhores práticas para captura, armazenamento e consumo de dados. A 14.0 promete resolver muitas dessas deficiências relacionando elementos tecnológicos como Big Data, CPS, IoT e Inteligência Artificial (IA) (MANZANO; LANGER, 2018). Atualmente já há empresas biofarmacêuticas, por exemplo, capazes de gerenciar várias linhas de produção (às vezes em locais diferentes) simultaneamente, com base em CPS, loT e Big Data e Al (DING, 2018).

Em relação aos sistemas baseados em IA (outro elemento estruturante da 14.0), estes oferecem modelos complexos para tomadas de decisão baseados em análises algorítmicas avançadas para vislumbrar conclusões ou previsões a partir dos conjuntos de dados disponíveis (Big Data). No campo da IA, o Machine Learning ( $\mathrm{ML}$ ) pode ser descrito como uma maneira de obter a IA através de cálculos rápidos que medem todas as opções possíveis para encontrar uma solução para uma determinada situação. O Deep Learning (DL) usa algoritmos baseados na estrutura e função do conhecimento humano para transformar dados através de camadas de processamento (OZTEMEL; GURSEV, 2018). Juntas, essas tecnologias fornecem as informações e inteligência necessárias para soluções permanentes de melhoria contínua - uma das promessas da Pharma 4.0. No caso, por exemplo, de alterações no cultivo celular para produção de um lote de vacina ou biofármaco, esses modelos seriam capazes de elucidar qual parâmetro de processo estaria alterado através da análise dos dados coletados em tempo real. Alguns modelos além de identificarem, são capazes também de atuar diretamente no ajuste do parâmetro fora de controle.

Outro elemento estruturante abarcado pelos conceitos da 14.0 é a computação em nuvem (Clouding Computing). Tal elemento é fundamental para que 
informações e dados sejam facilmente acessíveis de qualquer lugar do mundo. Juntamente com outros elementos da 14.0, a computação em nuvem permite, por exemplo, um controle multilocal de um determinado processo de produção. Trabalhando juntos, os elementos BigData, Computação em Nuvem e IA apresentam uma nova maneira de aplicação da ciência para lidar com a natureza complexa da manufatura moderna. Eles fornecem a capacidade de permanentemente monitorar, controlar e tomar decisões sobre processos de produção descentralizados, onde equipamentos, dispositivos, processos, sistemas e operadores são fontes de dados contínuos. Além disso, fornecem possibilidades para a validação dos processos contínuos, tornando a manufatura mais prática, viável e econômica. A adoção dos processos contínuos, substituindo por muitas vezes a produção por lotes, é considerada uma tendência na indústria biofarmacêutica (MANZANO; LANGER, 2018).

A comunicação Machine-to-Machine (M2M), outro elemento estruturante, pode ser entendida como a comunicação entre máquinas vinculadas aos sistemas de automação fabris através da loT, permitindo que os equipamentos de linhas de produção troquem dados e informações entre si de forma independente e sem a necessidade de intervenção humana. $\mathrm{Na}$ era da 14.0 , os produtos são dotados de identificadores, como códigos de barras QR ou etiquetas RFID (outros elementos tecnológicos propostos pela 14.0), que após a digitalização enviam informações relevantes para os equipamentos de produção. Estes são capazes de conduzir o produto sem intervenção humana ao longo da linha de manufatura para executar a sequência de operações necessárias à fabricação desse próprio produto. No caso de falha do equipamento, por exemplo, as próprias máquinas, através da M2M, podem reorganizar a linha para produzir itens que não precisam passar pela máquina danificada ou até redirecionar o produto para outra máquina (SACOMANO; SÁTYRO, 2018a). Por outro lado, o fato das máquinas participarem diretamente de processos decisórios independentes ainda é visto com bastante cautela pela indústria biofarmacêutica e agentes reguladores, uma vez que qualquer decisão equivocada pode resultar em ameaças à vidas humanas (BRANKE. J, FARID. S, 2016). 
A combinação desses elementos tecnológicos tem o potencial para habilitar as chamadas Smart Factories (Fábricas Inteligentes), capazes de fabricar produtos de forma cada vez mais automatizada e eficiente através da comunicação virtual e integração entre máquinas, pessoas e recursos (TESSARINI; SALTORATO, 2018). Essas fábricas incluem sensores dos mais variados tipos e complexidade que coletam, por exemplo, dados de processos em tempo real sem interromper a fabricação e permitindo o compartilhamento on-line pelos membros da empresa (MANZANO; LANGER, 2018). Nas fábricas inteligentes mais automatizadas, há também a presença de variados atuadores que, com base nos sinais elétricos recebidos dos sensores, realizam intervenção no mundo virtual através de comandos digitais (dados por máquinas, equipamentos ou pessoas), tais como abertura ou fechamento de válvulas, força mecânica ou aquecimento e resfriamento de um meio reacional, por exemplo (SACOMANO; SÁTYRO, 2018a). Esse tipo de mecanismo é de grande valia em todas as etapas dos processos produtivos de biomedicamentos, desde a produção do Ingrediente Farmacêutico Ativo até o Processamento Final (envase, liofilização, rotulagem e embalagem).

Sobre os elementos tecnológicos considerados complementares, KELLER et al. (2018) descrevem o uso e a validação de robôs assépticos para fins de produção. Durante a validação, um modelo de robô (chamado de 6 eixos) foi testado sob vários aspectos do GMP (Good Manufacturing Practices) estabelecidos pelos órgãos reguladores. Os testes atenderam satisfatoriamente às especificações estabelecidas. O uso de robôs assépticos é crítico e fundamental porque muitos processos na indústria biofarmacêutica exigem o máximo de limpeza possível especialmente aqueles para a fabricação de produtos estéreis (por exemplo, biofarmacêuticos injetáveis) (KELLER et al.., 2018). A IA contribuirá também para o progresso de equipes de robôs que cooperam e colaboram na execução de determinadas tarefas definidas para fins específicos que, em alguns casos, os humanos podem não ser capazes de realizá-las (OZTEMEL; GURSEV, 2018). O uso desses robôs também pode ser importante em tarefas demasiadamente repetitivas ou para reduzir a exposição do operador a riscos ergonômicos, químicos ou biológicos (riscos que frequentemente ocorrem em processos biotecnológicos) (MARKARIAN, 2019). 
A impressão 3D (ou manufatura aditiva) pode funcionar como uma alternativa complementar, inserida no contexto da 14.0, para produção rápida em resposta a serviços de demanda personalizados ou customizados. Assim como usamos impressoras tradicionais em casa, uma impressora 3D pode ser capaz de produzir medicamentos individualizados de alta qualidade instantaneamente em pequena escala e geralmente com baixa estabilidade (destinada ao uso imediato). É uma possibilidade interessante em situações de emergência ou para melhorar os serviços de medicamentos personalizados (seguindo uma tendência no mercado biofarmacêutico) (BRANCH; LADAGE; TSIOLIS, 2015). É possível fabricar um produto em um local com o comando de impressão 3D fornecido em outro. Além da própria produção, esse processo acelera a disponibilidade dos produtos onde serão utilizados. Além de peças industriais, podem ser feitas próteses, calçados, entre outros produtos diversos. Devido ao seu amplo campo de uso, a impressão 3D deve trazer grandes benefícios (SACOMANO; SÁTYRO, 2018a).

Ainda no contexto dos elementos tecnológicos da 14.0, as fábricas inteligentes também são dotadas de interessantes softwares relacionados às metodologias como realidade virtual, realidade aumentada, simulações e prototipagem virtual. Essas tecnologias possibilitam, por exemplo, que os usuários enxerguem e aprendam sobre um dado processo produtivo antes de serem produzidos no mundo real (criação de protótipos virtuais). Essas técnicas fornecem grandes benefícios, especialmente na concepção de produtos e sistemas de produção (OZTEMEL; GURSEV, 2018). Com a utilização de óculos de realidade aumentada, por exemplo, um operador pode acessar informações sobre o desenho ou sequência na montagem de um sistema ou equipamento, ter ideia dos itens que precisam ser repostos em estoque, lugares de armazenar ou posicionar um determinado item, dentre outras várias funções. Enquanto a realidade aumentada complementa o que já se encontra em um dado local, a realidade virtual cria no local uma realidade que só existe no mundo virtual (SACOMANO; SÁTYRO, 2018a). As aplicações dessas tecnologias são diversas no campo biofarmacêutico. Podem simular desde a montagem e ocupação de espaço produtivo por uma linha de equipamentos até trazer benefícios de qualidade (checando se itens produzidos respeitam as especificações). 
Outro ponto importante é a realização de uma avaliação prévia sobre a integração entre os sistemas e tecnologias. É importante refletir que um elemento tecnológico pode não ter função, atividade ou utilidade sem a presença e integração com outros elementos. Alguns especialistas comparam o perfeito funcionamento dos elementos tecnológicos a uma orquestra. Todos os elementos tecnológicos precisam estar funcionando adequadamente e em perfeita integração entre eles para que a fábrica inteligente consiga atingir os objetivos a que se propõe, tal como a harmonia entre instrumentos e músicos de uma orquestra.

É interessante ter em mente que todos os elementos propostos pela 14.0 podem ser importantes. Porém, é fundamental que as empresas façam as escolhas das tecnologias a serem empregadas de acordo com a estratégia, missão, valores e objetivos da própria organização. As implantações devem ser avaliadas e estudadas minuciosamente, caso a caso. Recomenda-se fortemente que os gerentes e líderes pensem estrategicamente sobre qual o valor que cada tecnologia pode agregar ao seu modelo de negócio.

As questões relacionadas à segurança cibernética, outro ponto a ser destacado em alguns trabalhos selecionados, encontram-se discutidas no item a seguir (parte de riscos e barreiras).

\subsubsection{Impactos da I4.0 na Indústria Biofarmacêutica}

Em geral, a maioria dos documentos coletados na RSL abordam possíveis impactos a serem encontrados na implantação dos conceitos e elementos 14.0 no setor biofarmacêutico.

Sobre os benefícios (Figura 6), a expectativa é que a adoção de novas tecnologias baseadas na 14.0 auxilie as empresas biofarmacêuticas no estabelecimento de processos fabris mais robustos, flexíveis e velozes, com menos interrupções não planejadas, menos defeitos em equipamentos, melhor atendimento aos prazos e gerenciamento da qualidade mais ágil com monitoramento, análises e processos decisórios em tempo real (AMERICAN PHARMACEUTICAL REWIEW, 2018)(MARKARIAN, 2018a). 
Figura 6 - Elementos tecnológicos e possíveis benefícios

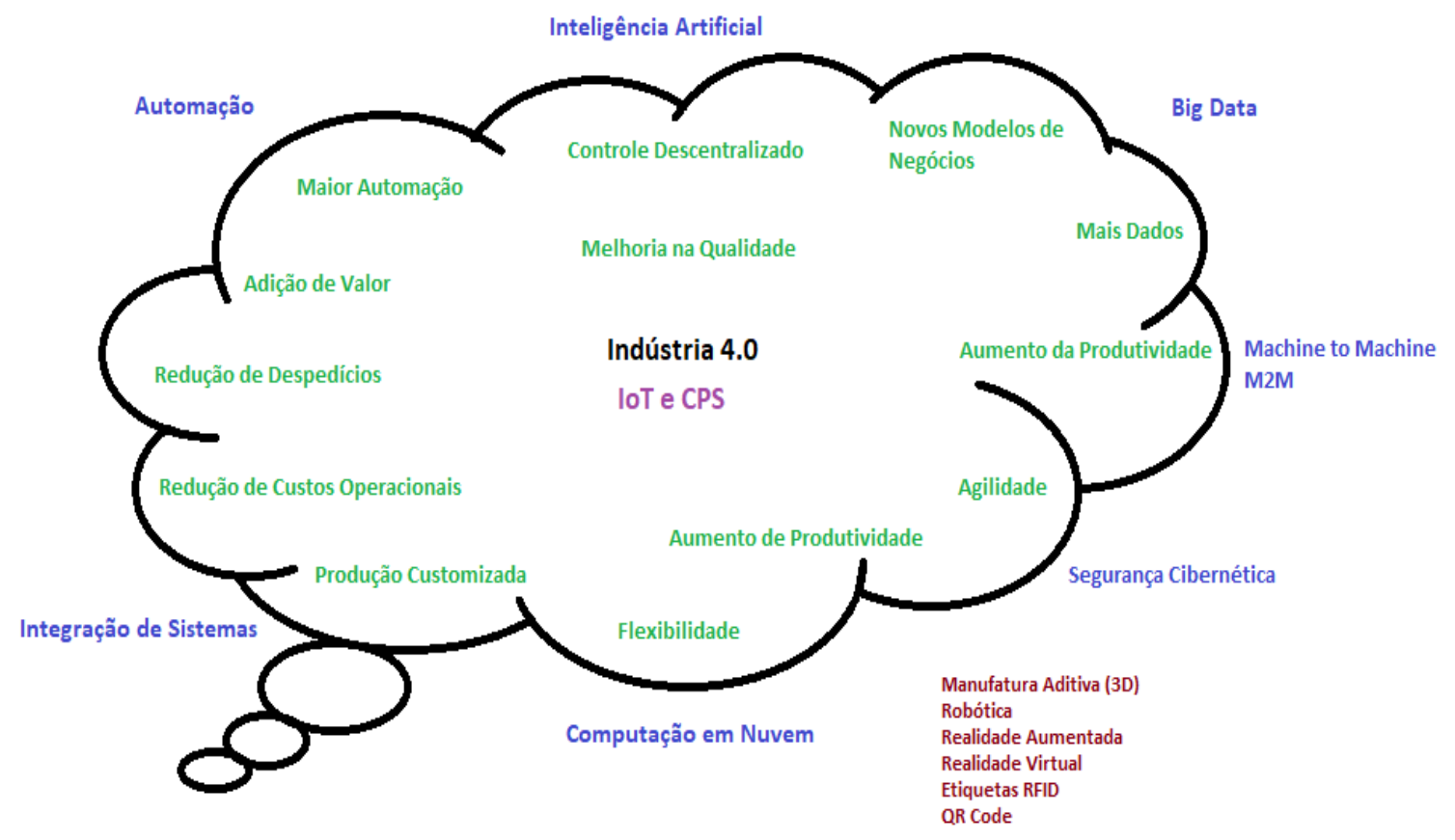

Fonte: Elaboração própria

Além de aumento da produtividade, os elementos tecnológicos da 14.0 permitirão, através da detecção de características que inviabilizariam a continuidade de um lote por exemplo, uma redução considerável do desperdício em horas trabalhadas, consumo de energia e, sobretudo, matérias primas e produtos (OZTEMEL; GURSEV, 2018)(GAERTNER, 2015). Consequentemente, a redução dos custos operacionais é outro benefício esperado no campo biofarmacêutico já verificada em outra áreas de atuação (BERTOLA; TEUNISSEN, 2018).

Conforme já pontuado na parte introdutória, produtos obtidos em sistemas vivos são normalmente instáveis e imprevisíveis. Portanto, é extremamente útil a utilização dos elementos da 14.0 para uma monitorização intensa, robusta e rigorosa dos processos produtivos com dados gerados continuamente em tempo real que permitem corrigir falhas durante a produção, predizer problemas com equipamentos, minimizar possibilidade de produtos indesejados e consequentemente aumentar a produtividade. Em um processo de fermentação ou propagação celular, por exemplo, quanto mais monitorado estiver o meio reacional (contendo as células que funcionam como uma espécie de fábrica), maior a possibilidade de obtenção dos produtos desejados. 
Outro ponto interessante é que alguns documentos coletados descrevem a indústria farmacêutica como ainda baseada no controle produtivo somente ao final de cada lote. A 14.0 fornece serviços e soluções avançadas de controle de processo (APC) que buscam integrar as tecnologias analíticas usadas para esse fim. Comparada à estratégia convencional, a aplicação dos elementos da 14.0 vai além do simples controle de processos. O nível mais alto de controle e monitoramento (baseado em algoritmos complexos) permitirá análises preditivas e ações de manutenção preditiva em linhas de produção ou equipamentos de processo (evitando falhas) (HAUSNER; ROMAÑACH, 2017)(ROMERO-TORRES et al.., 2018). Em geral, como os equipamentos produtivos nesse setor normalmente precisam ser assépticos (submetidos por muitas vezes à agentes de limpeza agressivos), muitos deles apresentam episódios de paragens recorrentes. É importante que os desgastes desses equipamentos possam ser detectados de forma preditiva para que ações possam ser tomadas antecipadamente.

É interessante também nesse setor as perspectivas de processos produtivos cada vez mais automatizados com máquinas interagindo diretamente com outras máquinas e por consequência menos dependentes de intervenções humanas. A maioria dos processos é realizada em áreas assépticas ou limpas, nas quais a presença de quaisquer particulados (a presença humana é a principal fonte deles) pode causar episódios de contaminação de lotes e prejuízos milionários. Outra consequência seria a redução da necessidade de altos investimentos na construção e manutenção de salas limpas.

Em relação aos processos inteligentes, no caso de um sensor de temperatura ou pH posicionado em um determinado ponto de um bioprocesso, por exemplo, seria possível transmitir os valores coletados a uma central para ser rapidamente acessada pela Internet pelo supervisor em tempo real e de qualquer lugar. No caso de sensores inteligentes, eles podem capturar os valores e ainda compará-los diretamente aos valores padrão programados. Dependendo da diferença, os sensores podem emitir sinais de aviso ao computador ou até mesmo comandar atuadores para fornecer a correção de temperatura ou pH sem nenhuma intervenção humana (SACOMANO; SÁTYRO, 2018a). 
Outro ponto importante é que os registros digitalizados substituirão gradualmente a entrada manual de dados. Os sensores incorporados coletam dados dos processos e os encaminham para os computadores em nuvem para que possam ser analisados, armazenados e rastreados (MANZANO; LANGER, 2018). Além da economia de papel, os registros eletrônicos atendem melhor os desejos das GMPs, pois dificultam a manipulação indevida de dados para burlar as inspeções (GAERTNER, 2015). No geral, espera-se que os dados digitalizados sejam armazenados de forma mais confiável e simples de rastrear. Como o setor biofarmacêutico é altamente regulado, a quantidade de papel gerado em documentação de processos é extremamente alta.

Outra questão recorrente é a dificuldade de tomada de decisão como resultado da impossibilidade de uma análise de dados e informações mais detalhada dos processos. Por exemplo, a avaliação de possíveis impactos ambientais por um processo bioquímico deve verificar as informações coletadas de várias fontes, como bancos de impacto ambiental, histórico de conformidade regulatória, entre outras. A conexão direta entre loT, BigData e computação em nuvem permitirá as empresas biofarmacêuticas verificar e avaliar de forma mais clara e confiável os dados disponíveis. Os gerentes serão capazes de usá-los para apoiar tomadas de decisão mais rápidas, precisas e independentes (FESTA et al.., 2018)(DING, 2018). Essas ferramentas tecnológicas permitirão que as empresas definam melhores práticas, indicadores de desempenho mais precisos e, consequentemente, tenham melhores resultados.

A possibilidade de produtos mais customizados ou direcionados à públicos menores é outro mote da 14.0. Essa é uma perspectiva interessante, já que é comum um determinado tipo de biomedicamento (proteínas terapêuticas, por exemplo) atender a um número reduzido de pacientes. Dessa forma, a expectativa é que os elementos da 14.0 possam oferecer processos produtivos mais enxutos que compensem a produção em escalas menores. Assim, haveria a possibilidade de uma produção que atendesse um público mais direcionado. Conforme enfatizado por alguns autores, as fábricas com estruturas modulares permitem uma maior flexibilidade para fabricação de diferentes produtos e também contribuirão para esse fim (HAMMER, 2018). As fábricas que não projetarem previamente essa 
necessidade correm o risco de tornarem-se "engessadas" e consequentemente não aproveitarem oportunidades que possam surgir.

Sobre o futuro dos processos produtivos na indústria biofarmacêutica, alguns estudos abordam uma tendência de utilização cada vez maior dos sistemas de uso único (single-use) acoplados ou não aos equipamentos. Este é considerado também um grande desafio para essa área. Dependendo da atividade, esses sistemas podem exigir esforços manuais significativos para conectar todas as partes necessárias ao processo. Os gráficos inteligentes podem ajudar os operadores a visualizar instruções e sistemas de reconhecimento que podem ser integrados às plataformas de controle para confirmar a colocação das peças nos locais corretos. Por exemplo, um sistema de controle pode ser configurado para exigir que o operador registre o código de barras em cada peça descartável para garantir a montagem correta e o registro adequado do lote (AMERICAN PHARMACEUTICAL REWIEW, 2018)(MARKARIAN, 2018a).

A perspectiva também é de uma comunicação mais eficiente e ágil entre os departamentos e unidades das empresas, seus fornecedores e clientes ao redor do mundo ao longo de toda a cadeia logística, permitindo também a fabricação de biomedicamentos que cheguem ao consumidor de forma mais veloz e customizada. Através de modernos simuladores virtuais, a expectativa também é de que novos produtos possam ser avaliados e lançados no mercado sem a necessidade de ocupação da fábrica. Logo, há uma possibilidade de que novos modelos de negócios possam surgir a partir destes novos cenários.

Quadro 5 - Principais impactos relatados na literatura - adaptados à indústria biofarmacêutica

\begin{tabular}{|c|c|}
\hline Principais Benefícios & Principais Barreiras \& Riscos \\
\hline Redução de Custos Operacionais & Alto Nível de Investimento \\
\hline Aumento de Produtividade & Resistência organizacional (cultural) \\
\hline Melhor atendimento aos prazos & Ausência de profissionais qualificados \\
\hline Flexibilização das linhas produtivas & Ameaça à Segurança da Informação \\
\hline Customização & Integração de equipamentos e tecnologias \\
\hline Melhoria na Qualidade & Baixa estrutura de TI \\
\hline Redução de Desperdícios & Gestores imbuídos no tema I4.0 \\
\hline Lançamento de Novos Produtos & Ausência de cases relatados na literatura \\
\hline Projeção de Novos Modelos de Negócio & Alto grau de exigências regulatórias \\
\hline
\end{tabular}

Fonte: Elaboração Própria 
No que se refere às principais restrições, alguns pontos são frequentemente citados na literatura selecionada e utilizada neste estudo.

A ausência ainda de profissionais capacitados e com as qualificações necessárias é umas das maiores preocupações associadas à 14.0. Em um dos estudos coletados, por exemplo, os autores apontam algumas restrições para que o APC seja mais aplicado na bioindústria farmacêutica. A primeira restrição, relatada com certa frequência na literatura, é a ausência de profissionais que combinem o domínio do conhecimento em modelagem de sistemas com as habilidades de análise de processos farmacêuticos. Essa combinação interdisciplinar é crítica não só quanto aos modelos de APC, mas também para a implantação de outros elementos da 14.0. A segunda restrição é sobre a incerteza quanto ao desempenho e, consequentemente retorno de investimento, que a APC pode alcançar. Esse é outro desafio descrito em alguns artigos para a 14.0 em geral, uma vez que há poucos relatos científicos de experiências e cases na indústria biofarmacêutica (ROMERO-TORRES et al.., 2018).

A integração de sistemas é outro ponto extremamente desafiador em relação à 14.0. A principal razão é que muitos equipamentos ou dispositivos trabalhando com sistemas desenvolvidos por seus fabricantes podem, em diversos casos, não se integrar a sistemas de outros fabricantes (ROMERO-TORRES et al.., 2018). Vários esforços estão sendo realizados para padronizar os sistemas empregados objetivando reduzir esse tipo de problema.

Diversos autores abordam também os riscos envolvidos no 14.0. A fragilidade dos sistemas de segurança da informação é frequentemente discutida. Estudos sugerem o uso de protocolos modernos para estabelecer um nível de segurança adequado. É uma boa prática separar os dados comerciais dos dados de produção em GMP (BPF) usando uma espécie de "zona segregada industrial" (MARKARIAN, 2018a). É altamente desafiador manter os níveis de segurança atualizados com a quantidade de dados coletados como resultado da crescente conectividade entre sistemas, equipamentos e processos que se comunicam por meio da loT. A conexão móvel com acesso a serviços confidenciais de dados de processos executados por telefones celulares ou tablets é um problema que os fabricantes devem considerar. 
As tecnologias estão disponíveis, mas devem ser cuidadosamente gerenciadas para que a segurança dos dados seja mantida intacta.

Outro ponto interessante é que alguns estudos comparam o ritmo mais moroso de inserção dos conceitos e elementos da 14.0 na indústria biofarmacêutica com a experiência verificada em outras áreas, como uma empresa de semicondutores do Vale do Silício e outra de tecidos da moda (ROMERO-TORRES; MOYNE; KIDAMBI, 2017)(BERTOLA; TEUNISSEN, 2018). A velocidade mais lenta de implantação na indústria biofarmacêutica pode ser justificada por alguns fatores, dentre os quais destacaria o alto nível de regulação no setor (a área lida diretamente com vidas), a complexidade dos processos biotecnológicos e a incerteza de sucesso causada ainda pela ausência de cases relatados cientificamente na literatura.

A grande maioria dos documentos identificados sobre o tema foi encontrada em revistas eletrônicas especializadas na área biofarmacêutica e não nas bases científicas tradicionais. Provavelmente esse fato acontece em função da incipiência científica observada sobre o assunto. Como o tema da 14.0 é bastante recente, a maior parte dos artigos, trabalhos e publicações ainda se encontram nos sítios de associações, instituições e revistas especializadas. Os trabalhos científicos coletados que tratam especificamente do tema 14.0 aplicado à indústria biofarmacêutica foram publicados em sua esmagadora maioria nos últimos 5 anos, conforme ilustrado na Figura 7.

Figura 7 - Publicações por ano

\section{Publicações por Ano}

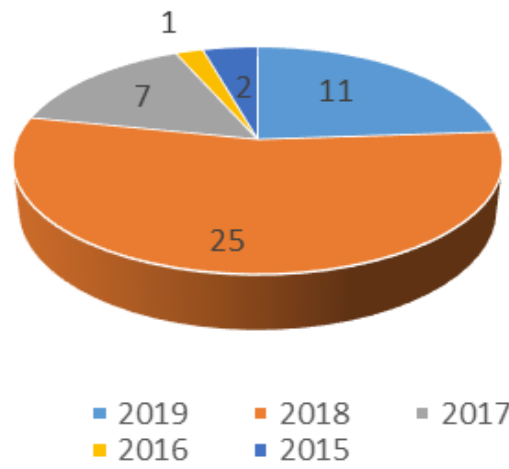

Fonte: Elaboração Própria 
Outro ponto interessante a ser observado é que a grande maioria dos documentos coletados nas bases científicas tradicionais aborda a indústria farmacêutica produtora de farmoquímicos (obtidos através de síntese química). Poucos estudos focam especificamente na produção de medicamentos por processos biológicos. Se por um lado esse fato possa desencorajar empresas do setor a investirem na 14.0, por outro é uma oportunidade interessante para que autores publiquem nas bases científicas tradicionais.

\section{CONSIDERAÇÕES FINAIS}

Em geral, os documentos selecionados e incluídos neste estudo de RSL indicam a necessidade preeminente da indústria biofarmacêutica evoluir na implantação de novas tecnologias em seus processos produtivos e detalham possíveis impactos a serem verificados na implantação dos elementos tecnológicos fornecidos pela 14.0 no setor.

A incipiência no tema na área pôde ser evidenciada pelo baixo número de documentos identificados nas bases de dados científicas tradicionalmente estabelecidas. A maioria dos documentos sobre o assunto ainda está disponível apenas em revistas especializadas na área. A incipiência pode ser causada por alguns fatores, como a rigidez dos sistemas regulatórios no setor, a complexidade dos processos biológicos e a ausência ainda de conhecimento científico sobre as consequências do alto investimento para implantação da 14.0 na área.

Como perspectivas futuras, há ainda existe um caminho longo e desafiador a ser trilhado para a implantação da 14.0 na indústria biofarmacêutica bem como na disseminação do conhecimento através de publicações, o que consequentemente abre um vasto campo de oportunidades a serem exploradas. É fundamental um maior estreitamento sobre o tema entre produtores com as agências reguladoras, a qualificação de profissionais multifuncionais capazes de entender as peculiaridades da área e a geração de publicações científicas que permitam troca mais intensa de conhecimento, informações e experiências.

\section{REFERÊNCIAS}

BARBOSA, A. A formação de competências para inovar através de processos de 
transferência de tecnologia : um estudo de caso - Universidade Federal do Rio de Janeiro, 2009.

BARENJI, R. V. et al.. Cyber-physical-based PAT (CPbPAT) framework for Pharma 4.0. International Journal of Pharmaceutics, [s.I.], v. 567, p. 118445, Feb. 2019. https://doi.org/10.1016/i.ijpharm.2019.06.036

BERTOLA, P.; TEUNISSEN, J. Fashion 4.0. Innovating fashion industry through digital transformation. Research Journal of Textile and Apparel, [s.I.], v. 22, n. 4, p. 352-369, 2018. https://doi.org/10.1108/RJTA-03-2018-0023

BRANKE. J, FARID. S, S. N. Industry 4 . 0: a vision also for personalised medicine supply chains? Cell Gene Ther. [s.I.], v. 2, n. 2, p. 263-270, 2016.

https://doi.org/10.18609/cgti.2016.027

COELHO, P. Rumo à Industria 4.0. Dissertação (Mestrado) - Universidade de Coimbra, 2016. Disponível em: https://estudogeral.uc.pt/handle/10316/36992.

CONFORTO, E. C.; AMARAL, D. C.; SILVA, S. L. Da. Roteiro para revisão bibliográfica sistemática: no desenvolvimento de produtos e GP. In: CONGRESSO BRASILEIRO DE GESTÃO DE DESENVOLVIMENTO DE PRODUTO, 8., 2011. [Anais...]. CNGDP 2011, [S.I.], no 1998, p. 1-12, 2011.

DAUDT, G.; WILLCOX, L. Reflexões críticas a partir das experiências dos Estados Unidos e da Alemanha em manufatura avançada. BNDES Setorial. 44. ed. Rio de Janeiro: [s.n.], 2016. p. 5-46.

DING, B. Pharma Industry 4.0: literature review and research opportunities in sustainable pharmaceutical supply chains. Process Safety and Environmental Protection, [s.l.], v. 119, p. 115-130, 2018. https://doi.org/10.1016/j.psep.2018.06.031

FESTA, G. et al.. Big data for big pharma: harmonizing business process management to enhance ambidexterity. Business Process Management Journal, [s.I.], v. 24, n. 5, p. 1110-1123, 2018. https://doi.org/10.1108/BPMJ-10-2017-0272

KELLER, M. et al.. Optimized robot systems for future aseptic personalized mass production. Procedia CIRP. [s.I.], v. 72, p. 303-309, 2018. https://doi.org/10.1016/j.procir.2018.03.066

KUTNJAK, A.; PIHIRI, I.; FURJAN, M. T. Digital transformation case studies across industries: Literature Review. [s.I.], p. 1293-1298, 2019.

https://doi.org/10.23919/MIPRO.2019.8756911

MANZANO, T.; LANGER, G. Getting ready for pharma 4.0: data integrity in cloud and big data applications. International Society for Pharmaceutical Engineering (ISPE), [s.I.], p. 72-19, 2018. https://doi.org/10.1177/030857599602000113

MARKARIAN, J. Industry 4.0 in biopharmaceutical manufacturing: modern technologies offer opportunities to increase manufacturing efficiency. BioPharm International, [s.I.], v. 31, n. 7, p. 36-38, 2018a.

MARKARIAN, J. Pharma 4.0. Pharmaceutical Technology, [s.I.], v. 42, n. 4, p. 24, $2018 b$.

MARKARIAN, J. Embracing the digital factory for bio/pharma manufacturing. 
Pharmaceutical Technology, [s.I.], v. 43, n. 3, p. 16-21, 2019.

NARGUND, S.; GUENTHER, K.; MAUCH, K. The Move toward Biopharma 4.0. Genetic Engineering and Biotechnology News, [s.I.], v. 39, n. 6, p. 53-55, 2019. https://doi.org/10.1089/gen.39.06.18

OZTEMEL, E.; GURSEV, S. Literature review of Industry 4.0 and related technologies. Journal of Intelligent Manufacturing, [s.I.], Jan. 2018. https://doi.org/10.1007/s10845$\underline{0181433-8}$

ROMERO-TORRES, S. et al.. Biopharmaceutical process model evolution- enabling process knowledge continuum from an advanced process control perspective. American

Pharmaceutical Review, [s.I.], 2018.

ROMERO-TORRES, S.; MOYNE, J.; KIDAMBI, M. Towards pharma 4.0; Leveraging lessons and innovation from Silicon valley. American Pharmaceutical Review, [s.I.], v. 7, n. 1, 2017.

SACOMANO, J.; SÁTYRO, W. Indústria 4.0: conceitos e elementos formadores. In: EDGARD BLUCHER LTDA. (Org.). Indústria 4.0: conceitos e fundamentos. São Paulo: [s.n.], 2018a. p. 27-47.

SACOMANO, J.; SÁTYRO, W. Introdução. In: EDGAR BLUCHER LTDA. (Org.). Indústria 4.0: conceitos e fundamentos. São Paulo: [s.n.], 2018b. p. 17-27.

SILVA, F.; CAULLIRAUX, H. A desverticalização no setor de produção de biomedicamentos e a utilização das empresas cmos (contract manufacturing organization). Revista Produto \& Produção, [s.I.], v. 17, n. 4, p. 1-18, 2016. https://doi.org/10.22456/1983-8026.63121

TESSARINI, G.; SALTORATO, P. Impactos da indústria 4.0 na organização do trabalho: uma revisão sistemática da literatura. Revista Produção Online, [s.n.], v. 18, n. 2, p. 743769, 2018. https://doi.org/10.14488/1676-1901.v18i2.2967

YU, L. X.; KOPCHA, M. The future of pharmaceutical quality and the path to get there. International Journal of Pharmaceutics, [s.I.], v. 528, n. 1-2, p. 354-359, 2017. https://doi.org/10.1016/j.ijpharm.2017.06.039

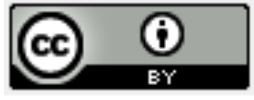

Artigo recebido em: 15/11/2019 e aceito para publicação em: 05/06/2020

DOI: http://dx.doi.org/10.14488/1676-1901.v20i2.3843 